\title{
Sôbre a germinação do mogno (aguano) Swietenia macrophylla King
}

\author{
Vivaldo Campbell de Araujo(*) \\ Instituto Brasileiro de Desenvolvimento \\ Florestal
}

\begin{abstract}
SINOPSE
O alto valor comercial da Swietenia macrophyila King, com habitat natural na Amazônia e grande exploração, moveram o autor conhecer suas características silviculturais para a região, estudando na oportunidade a germinação pelo tipo de colheita da semente, viabilidade quanto a armazenagem, profundidade da semeadura, tipo de solo ideal.
\end{abstract}

\section{INTRODUÇÃO}

Um trabalho sôbre a germinação de Swietenia macrophylla King, nos dias atuais, não parece apresentar grandes novidades, partindo-se do princípio de que esta espécie, como algumas outras Meliaceae (Cedrela spp., Carapa sp.), já tinham sido alvo de estudos em vários países, dado o alto valor comercial de suas madeiras.

Considerando que os estudos anteriormente realizados pelos diferentes autores, Quimpo, T. (1937); Marrero, J. (1949); Marie, E. (1949); Chinte, F. O. (1952); Bascő́pe F. et. al. (1957); Lamprecht \& Hueck (1959); Marcano; A. R. (1963), foram em outras regiões, apresentando controvérsias, é que procuramos também realizar algumas observações silviculturais com esta espécie para a Região Amazônica (Manaus) .

Sendo a Região Amazônica, uma área bem diferente nas condições climáticas e edáficas. daquelas pesquisadas pelos diversos autores, é também uma área de ocorrência natural do Mogno (Record \& Hess, 1949) (fig. 1).

A ocorrência natural do Mogno na região, entretanto, só tem favorecido até o presente a exploradores e aventureiros que, vindos de todas as regiões do país e do estrangeiro, extraem sem controle milhares de árvores anualmente, vendendo a madeira a preços astronômicos (Souza, 1967).
O uso irracional das terras no empirismo da lavoura itinerante, a carência de dados silviculturais, de um manejo florestal adequado, a marcha desenvolvimentista e de ocupação, ajudado pela fome nacional e internacional de madeiras, põem em ameaça a Amazônia, enfàticamente a Amazônia Brasileira.

A carência nacional e internacional de madeiras já impõe um cultivo de espécies, que além do alto valor comercial sejam também de crescimento rápido.

Diante do exposto, uma pesquisa realizada sôbre o Mogno para a região, como a que esta. mos apresentando, julgamos perfeitamente justificada.

Os testes de germinação foram realizados no viveiro florestal do Centro de Pesquisas Florestais - Reserva Florestal Ducke (Manaus Am), do Instituto Nacional de Pesquisas da Amazônia.

\section{MATERIAL}

O material para êste estudio foi todo proveniente de Itacoatiara (Município do Amazonas), colhido pelo Autor de árvores de plantações com 18 e 19 anos (fig. 2, 3, 4 e 5), realizadas por Emile Chenivesse.

A queda das fôlhas ocorre no mesmo tempo da deiscência dos frutos (julho - agôsto setembro), para uma floração imediatamente à renovação foliar (agôsto - setembro); portanto o desenvolvimento dos frutos (floração a deiscência) é aproximadamente um ano.

Parte das sementes foi colhida no chão, pela deiscência natural dos frutos, parte foi obtida de frutos apanhados em estado de maturação bem adiantado.

Os frutos apanhados, colocados em ambiente natural, 2 a 3 dias depois apresentavam(*) - Trabalho realizado no Instituto Nacional de Pesquisas da Amazônia e financiado pelo Conselho Nacional de Pesquisas. 


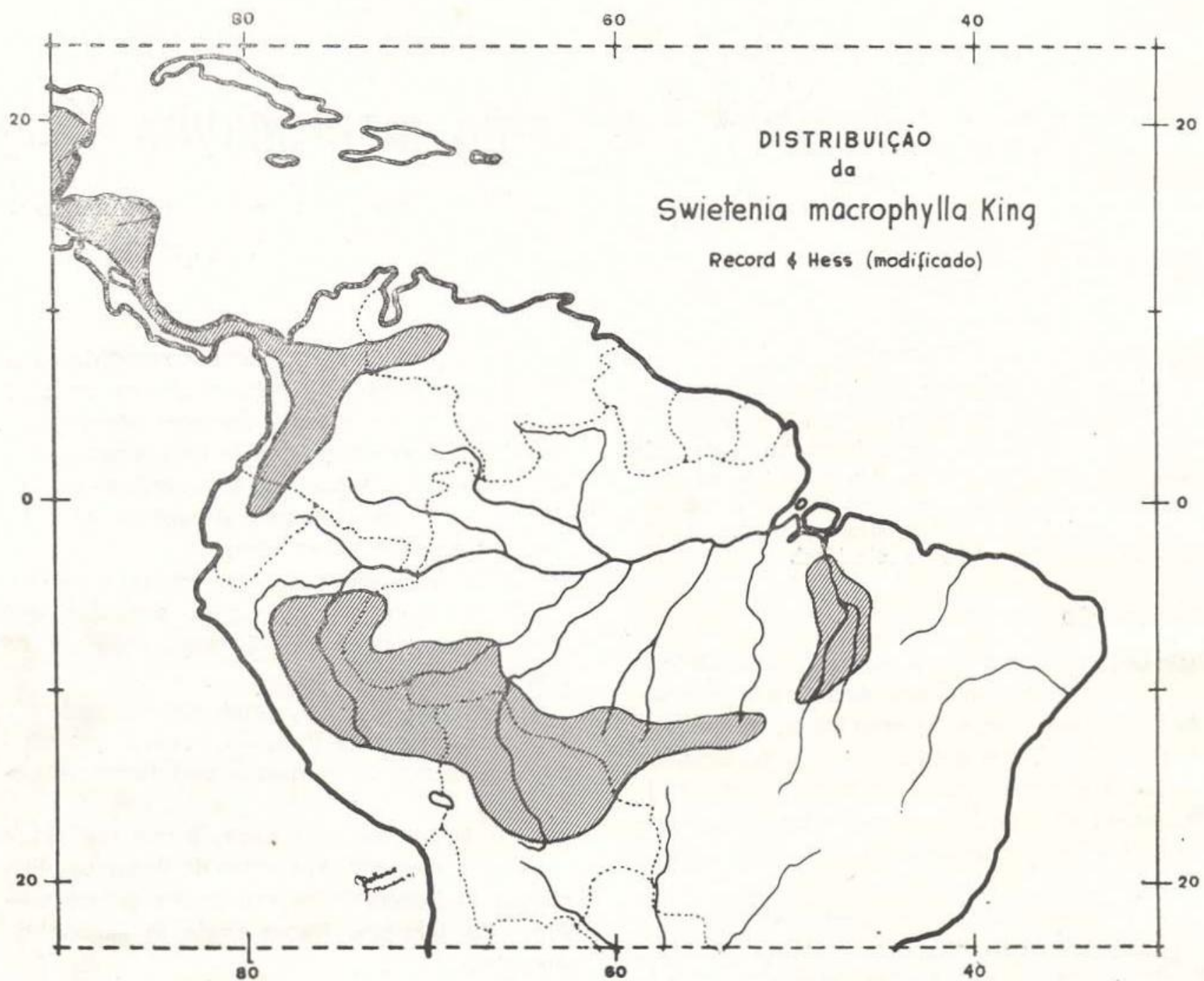

Fig. 1 - Configuração da ocorrência de mogno (Aguano) Swietenia macrophylla King, na América do Sul.

se abertos, o que permitia a retirada das sementes (fig. 5-A). Êste fato merece destaque em virtude da colheita após deiscência natural ser dificultosa, principalmente em área de mata, porque as sementes podem dispersar-se a grandes distâncias, carreadas pelos ventos, ou mesmo pela mistura com a folhagem do chão.

As sementes são de côr marrom escuro, aladas, com 10 a $13 \mathrm{~cm}$ de comprimento e com 1,5 a $2,5 \mathrm{~cm}$ de largura. Apesar de grandes, são muito leves, porque o pericarpo consiste em suas partes mais grossas de tecidos esponjosos e cheios de ar. A amêndoa tem em média $2 \mathrm{~cm}$ de comprimento, por $1 \mathrm{~cm}$ de largura e 2 a $3 \mathrm{~mm}$ de espessura (fig. 5-B) .

$\mathrm{O}$ número de semente por $\mathrm{kg}$ (pêso médio) é de 1.600. O poder germinativo de sementes frescas é elevado, chegando de 85 a $95 \%$, de- crescendo em pouco tempo, se mantidas em condições ordinárias da Amazônia. Segundo Lamprecht \& Hueck (1959), conserva-se bem por um a dois anos, armazenadas a $4^{\circ} \mathrm{C}$ aproximadamente. Segundo Chinte (1952), a armazenagem em latas de carvão em pó e enterradas a $40 \mathrm{~cm}$ de profundidade no solo, mantém a viabilidade germinativa por 132 dias em 70 a $72 \%$.

\section{MÉToDos}

A semeação foi realizada obecendo 11 diferentes condições (A, B, C, D ....N) em 5 testes (I, II, II, IV e V).

A semeadura foi realizada com espaçamentos de $10 \times 10 \mathrm{~cm}$ diretamente no viveiro e em sacos plásticos. 


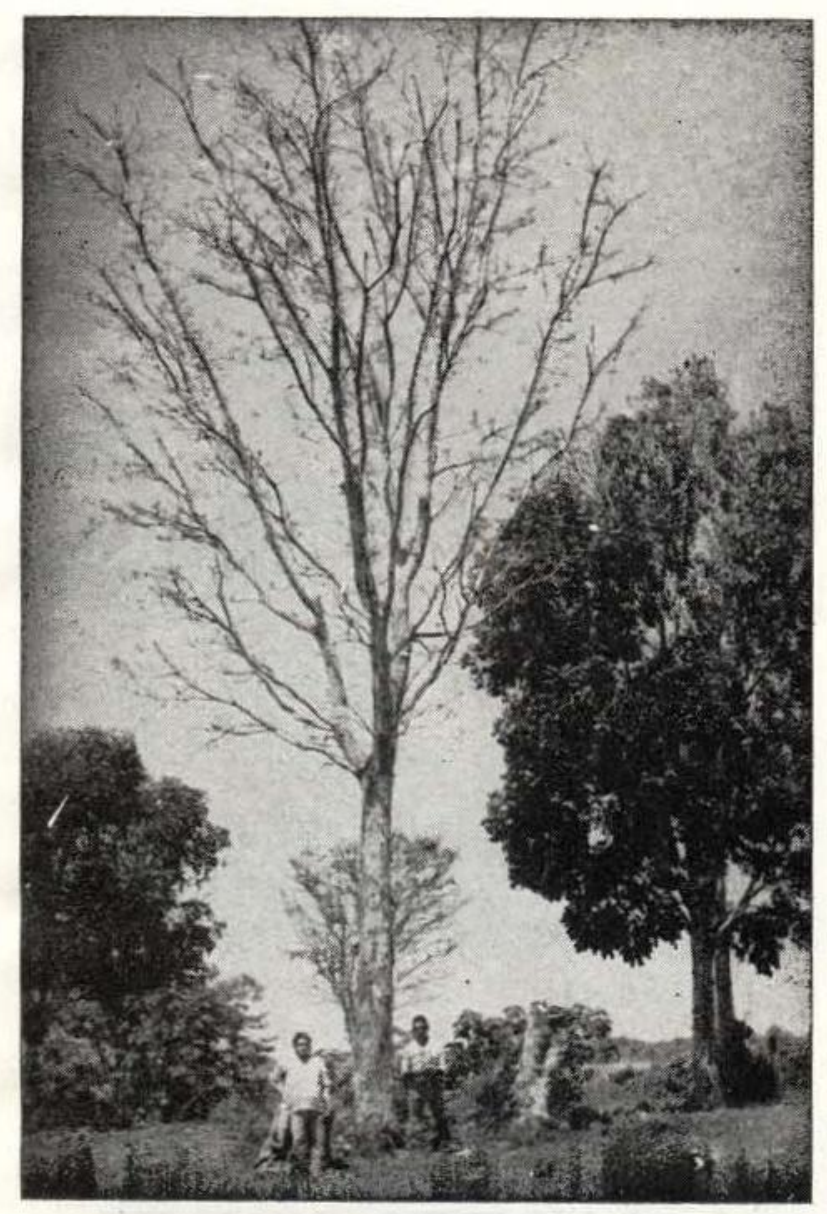

Fig. 2 - Ârvore de mogno, resultante de uma pequena plantação. No primeiro plano e ao fundo aparecem ár. vores completamente desfolhadas ao terminar a frutificação. Foto do Autor

TESTE I - Germinação de Swietenia macrophylla King, sua viabilidade quanto ao tipo de semente.

A) - Sementes apanhadas no chão provenientes de deiscência natural.

B) - Sementes de frutos maduros colhidos.

TESTE II - Germinação de Swietenia macrophylla King, quanto à profundidade da semeadura.

C) - Semeadura a $2 \mathrm{~cm}$ de profundidade, 3 dias após a colheita, com sementes colhidas de frutos maduros.

D) - Semeadura a $6 \mathrm{~cm}$ de profundidade, 3 dias após a colheita, com sementes colhidas de frutos maduros.
TESTE III - Germinação de Swietenia macrophylla King, quanto à sua viabilidade em relação à armazenagem $(30,45$ e 60 dias).

E, F e G) - Semeaduras com sementes colhidas no chão e armazenadas durante 30,45 e 60 dias, respectivamente.

TESTE IV - Germinação de Swietenia macrophylla King, quanto ao meIhcr tipo de solo.

H) - Em solo de terra preta comum.

I) - Em solo de terra preta do lixo e areia na proporção de $1 \times 1$.

J) - Em solo de terra preta do lixo, e areia e barro (argila) na proporção de $2 \times 1 \times 1$, respectivamente.

TESTE V - Germinação em saco plástico.

L) - Semeadura com sementes coIhidas de frutos maduros, a $2 \mathrm{~cm}$ de profundidade, 5 dias após a colheita em solo de terra preta.

M) - Semeaduras com sementes colhidas de frutos maduros, a $2 \mathrm{~cm}$ de profundidade, 5 dias após a colheita, em solo de terra preta do lixo e areia.

N) - Sementes de frutos maduros, semeadas a $2 \mathrm{~cm}$ de profundidade, em terra preta do lixo e árgila, com 5 dias após a collieita.

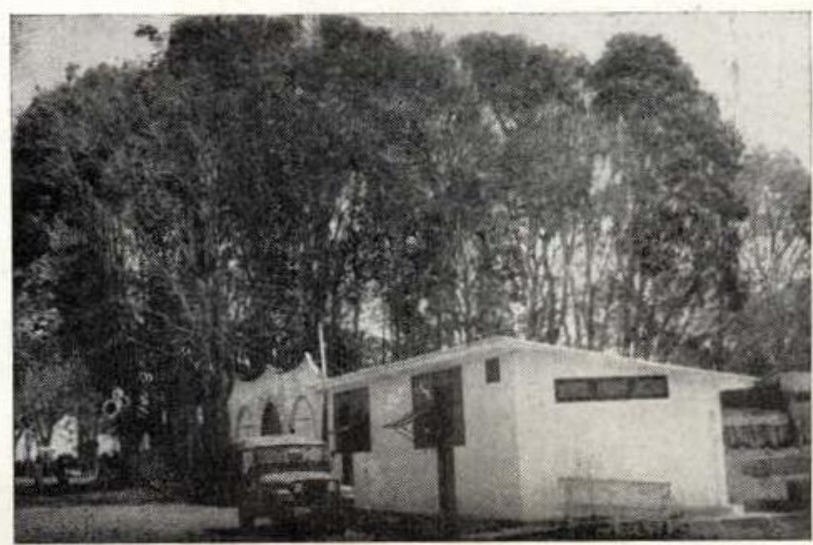

Fig. 3 - Grupo denso de mognos restante de um viveiro em Itacoatiara - Amazonas. Foto do Autor 
Anteriormente à semeação, foram realizados os testes de vitalidade (corte de 180 sementes) e seleção das sementes.

Vitalidade das sementes dos frutos colhidos $-100 \%$.

Vitalidade das sementes colhidas no chão $-92 \%$.

Os testes de germinação foram feitos utilizando-se número de sementes, com um mínimo de 100 em cada caso.

Preparo dos canteiros - os canteiros do viveiro, receberam terra preta do lixo e areia na proporção de $2 \times 1$, respectivamente, exceto nos Testes IV e $\mathrm{V}(\mathrm{H}, \mathrm{I}$ e $\mathrm{J})$, em que a nossa preo cupação foi saber qual o melhor tipo de solo.

Tratos do viveiro - irrigação diária e cobertura com ripado a $50 \mathrm{~cm}$ de altura.

Contagem da germinação - a germinação obedeceu a uma contagem diária, da primeira à última semente, sendo somente encerrada, quando após 10 observações seguidas, nada mais foi verificado (Gráf. I).

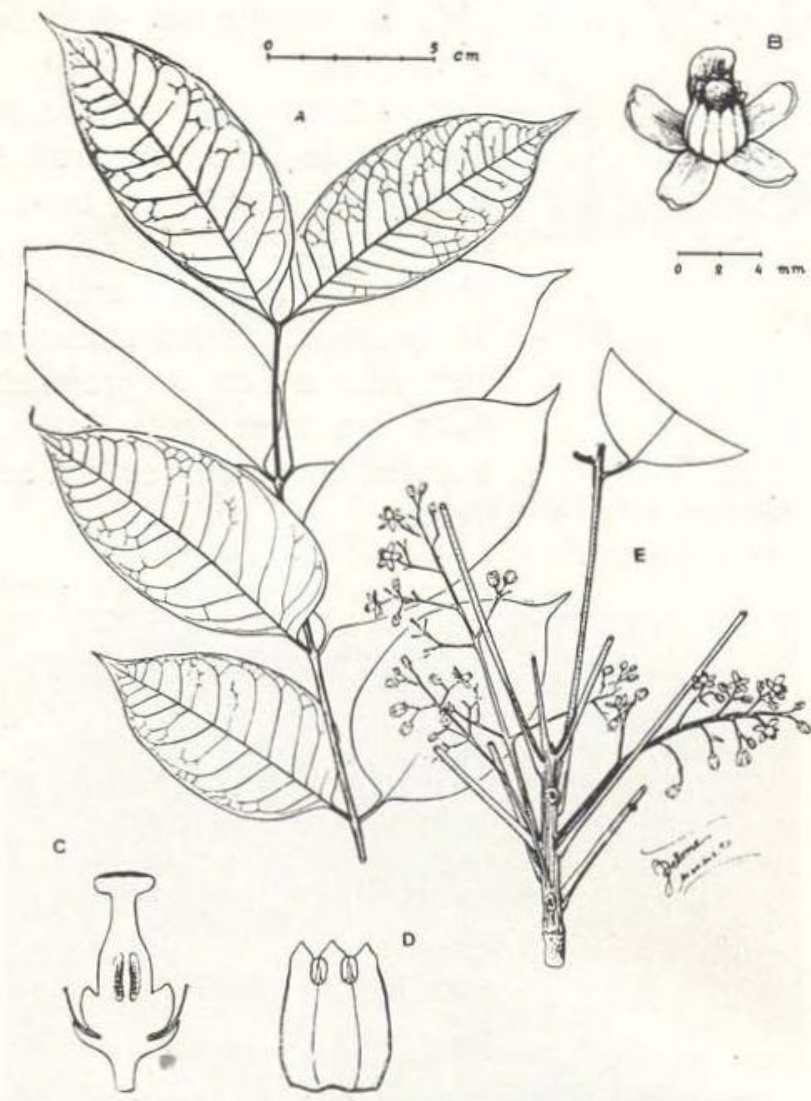

Fig. 4 - A) Ramo foliar; B) Flor; C) Gineceu; D) Androceu; E) Ramo florífero. Herbário do INPA, No 20.625 e 28.315

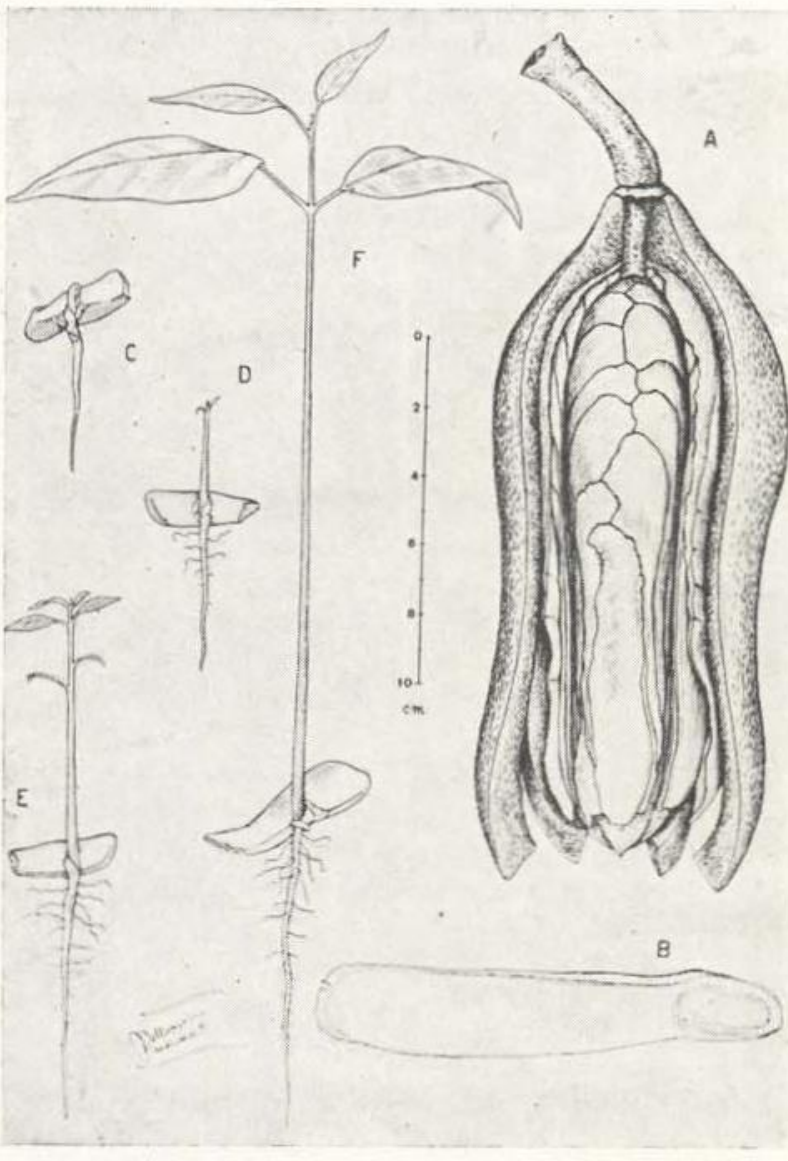

Fig. 5 - A) Fruto em deiscência, sem um ı́́culo para mostrar a disposição das sementes; B) Semente; C) Plântula ao iniciar a germinação, 15 dias após a semeadura; D, E e F) Plântula aos 18,24 e 35 dias, respectivamente

\section{RESULTADOS}

Os resultados obtidos no estudo da germinação como respostas aos testes realizados foram satisfatórios.

Para o Teste I, onde procuramos verificar a diferença no porcentual da germinação, comparando as sementes apanhadas no solo de deiscência natural com as sementes de frutos maduros coletados, constatamos que as sementes de frutos colhidos têm mais alto poder germinativo, fato que comprova a rápida perda de vitalidade da semente e de pêso (Quadro I).

O Teste II, motivo de muita controvérsia para diversos setores, - Quimpo, T. (1937), recomenda uma semeadura com profundidade de 4 a $8 \mathrm{~cm}$, afirmando ser esta última a de maior germinação; Chinte, F. O. (1952), manda que seja de 3 a $5 \mathrm{~cm}$ apenas; Lamprecht, $\mathrm{H}$. et. al. (1957), estabelece 2 a $5 \mathrm{~cm}$; Marie (1949), sugere $5 \mathrm{~cm}$. 
Verificando a melhor profundidade, tomamos apenas duas profundidade, a de 6 e $2 \mathrm{~cm}$. Os resultados foram opostos. Para a profundidade de $6 \mathrm{~cm}$ ocorreu um verdadeiro desastre (fig. 6 e 7). Aos 30 dias após a semeadura,

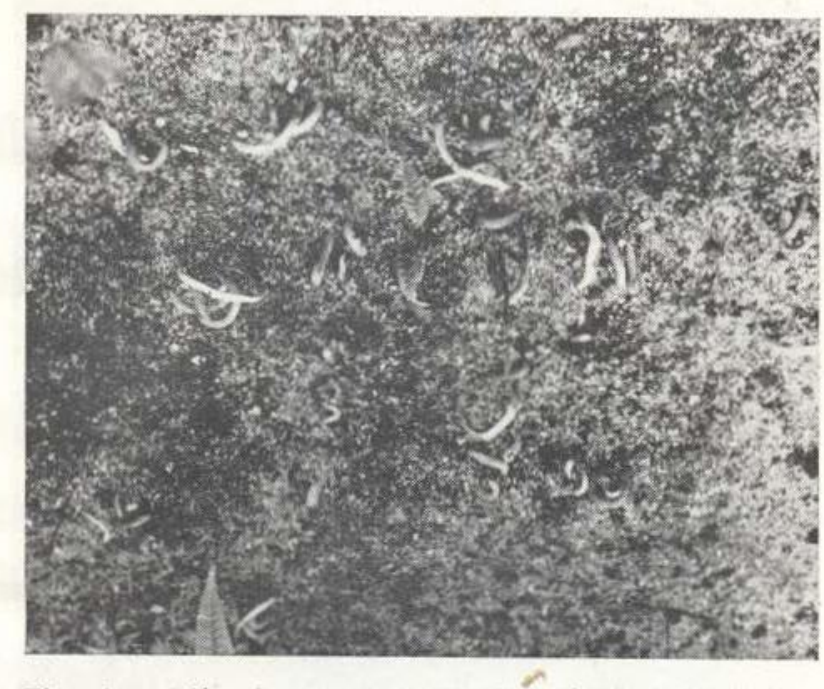

Fig. 6 - Plântulas no momento da retirada da camada de terra, aos 30 dias após a semeadura

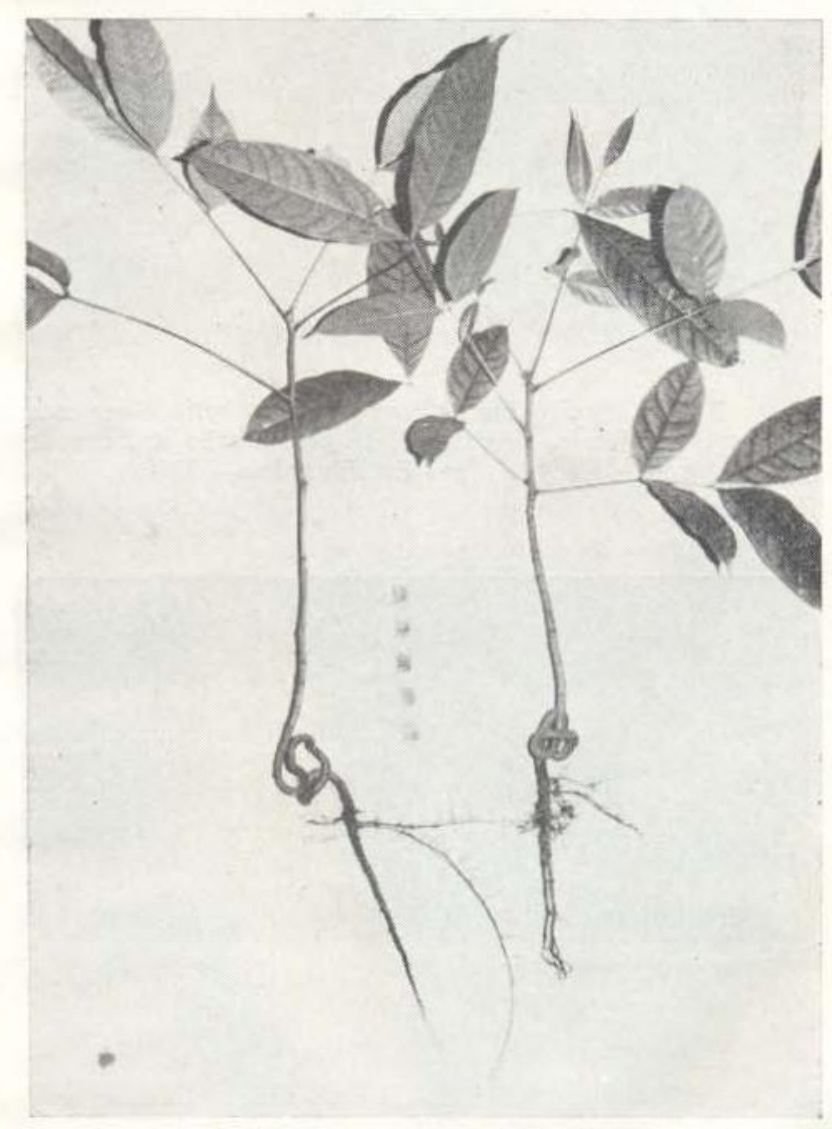

Fig. 7 - Plântulas aos 3 meses de idade, resultante da semeadura a $6 \mathrm{~cm}$ de profundidade, desenvolvida após a retirada da camada da terra notando que nada aparecia de germinação, retiramos $5 \mathrm{~cm}$ da camada de solo, verificando que as sementes haviam germinado em alta percentagem $(83 \%)$, porém que o caulículo não conseguira romper a camada de solo, enroscandose totalmente.

O mesmo tipo de semente, em mesmo tipo de solo, a $2 \mathrm{~cm}$ de profundidade, deu um resultado excelente (Quadro II, fig. 8 e 9) .

O Teste III confirmou, em parte, as afirmativas dos autores, que dão 45 dias, como período de vitalidade da semente de mogno. Verificamos que até 60 dias é possível se obter ainda $31 \%$ de germinação para as sementes aconaicionadas em ambiente natural.

Este fato mostra que o aconselhável é a imediata semeadura, pois a semente perde realmente o seu poder germinativo em pouco tempo (Quadro III, Gráfico II).

Para o Teste IV, obtivemos como resulta do que o melhor solo é a mistura de terra do lixo, areia e argila (tipo J), sendo assim, rico em matéria organıca, poroso e com boa reten. ção de umidade.

O solo do tipo $H$ (terra preta comum) é o de pior condição, por formar na superfície do canteiro, uma camada fina-compacta, a qual dificulta a absorção da água.

O tipo I (terra do lixo e areia) apesar de conter bastante matéria orgânica e permitir boa germinação $(90 \%)$, apresenta o inconveniente de aquecer muito fàcilmente (areia), produzindo a queima do colo da plantinha nos primeiros 60 dias após a germinação, num porcentual de mortalidade de até $30 \%$ (Quadro IV).

$\mathrm{O}$ Teste $\mathrm{V}$, quanto à germinação pròpriamente dita, desenvolveu-se bem ( $92 \%$ média), tanto em solo do tipo $H$, como nos demais (Gráfico) . Êste método apresenta um grave inconveniente, dado o grande desenvolvimento da raíz pivotante, a qual, com apenas um mês, já alcança o fundo do saco, recurvando-se na maioria dos casos, o que retarda o desenvolvimento da plântula.

Sendo a espécie de alta resistência ao transladamento de um lugar para outro, recomendamos o plantio definitivo com mudas de raíz nua, retiradas diretamente dos canteiros plásticos. 
A germinação que é do tipo hipógea, se inicia aos 13-16 dias nos casos normais, durante 9 a 10 dias.

O desenvolvimento aa plântula é bastante rápido (Fase $\mathrm{C}$ a $\mathrm{F}$ ), figura 5 .
Fase $C-15$ dias (média) após a semea- dura, o hepicótilo recurvado aparece à superfície. A radícula já tem maior desenvolvimento do que o caulículo, sem raizes secundárias.
Fase $D-18$ dias após a semeadura, o hepicótilo se estira, aparecen- do fôlhas primárias; são fôlhas pouco cloroficadas. Aparecem também as primeiras raízes se- cundárias.
Fase $E-24$ dias, aparece o primeiro par de fôlhas primárias. A raíz se desenvolve em igual tamanho ao caulículo, enriquecida de ráizes secundárias. A plântula nesta fase já alcança $7 \mathrm{~cm}$ de altura.

Fase $F-35$ dias após a semeadura, as fôlhas primárias se desenvolvem e são claramente alternas; são fôlhas oviformes, acumina. das, de base arredondadas, com $6-8 \mathrm{~cm}$ de comprimento por $2-3 \mathrm{~cm}$ de largura. As fôlhas primárias ainda são inteiras.

Mantém prêso ainda o pericarpo da semente, porém sem mais os rudimentos foliaressubulados.

Bom desenvolvimento racidular, Caulículo com 15 a $20 \mathrm{~cm}$ de altura.

Aos 3 meses de idade, pode medir até $30 \mathrm{~cm}$; aos 6 meses, $60 \mathrm{~cm}$, Idade e tamanho excelente para o plantio definitivo, podendo ser retardado para 8 ou 10 meses até 1 ano e meio, quando pode alcançar altura de 1,5 metro.

\section{CONCLUSÕEs}

Swietenia macrophylla King oferece grandes perspectivas para um trabalho de reflorestamento da Amazônia. É uma espécie que ocorre naturalmente ao Sul e Sudoeste da Amazônia Brasileira, em condições de ser bem estudada siiviculturamente.

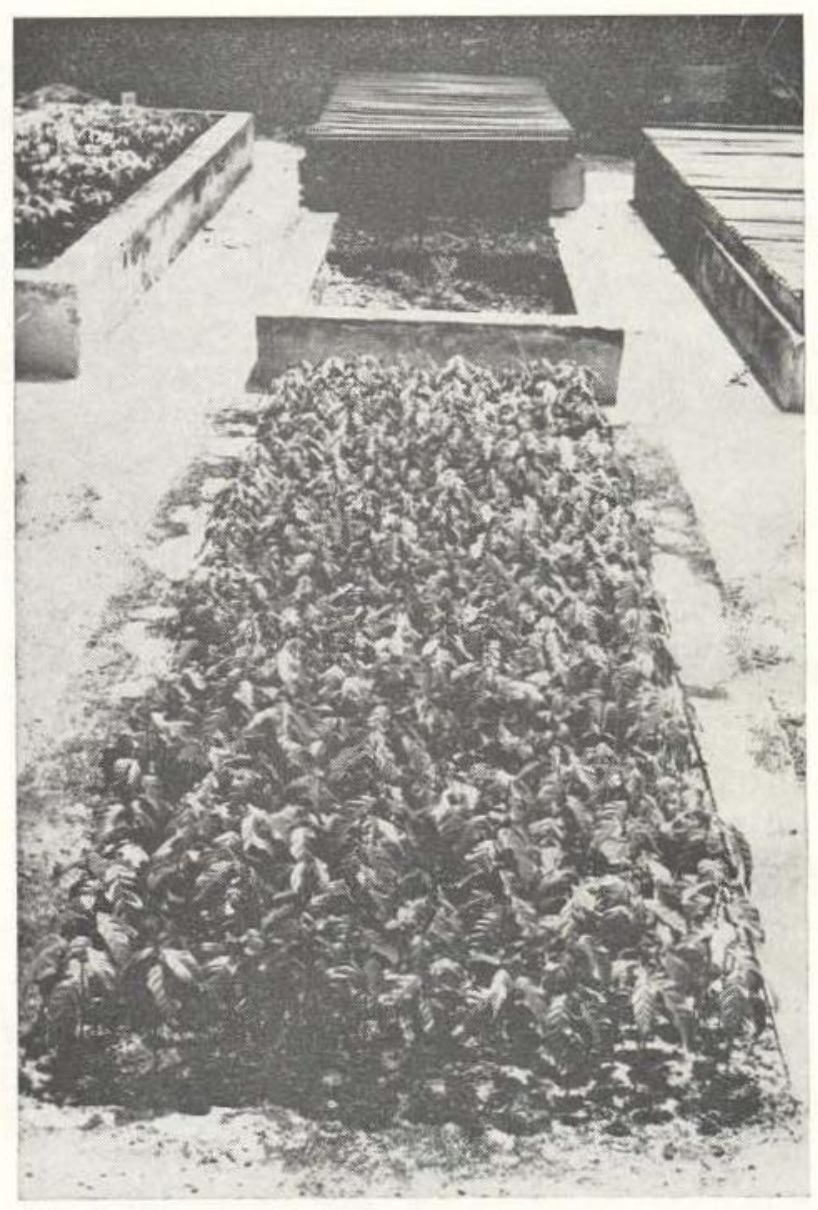

Fig. 8-Canteiro de Swietenia macrophylla King, aos 3 meses de idade, produzido da germinação a $2 \mathrm{~cm}$ de profundidade. Foto de Eduardo - INPA

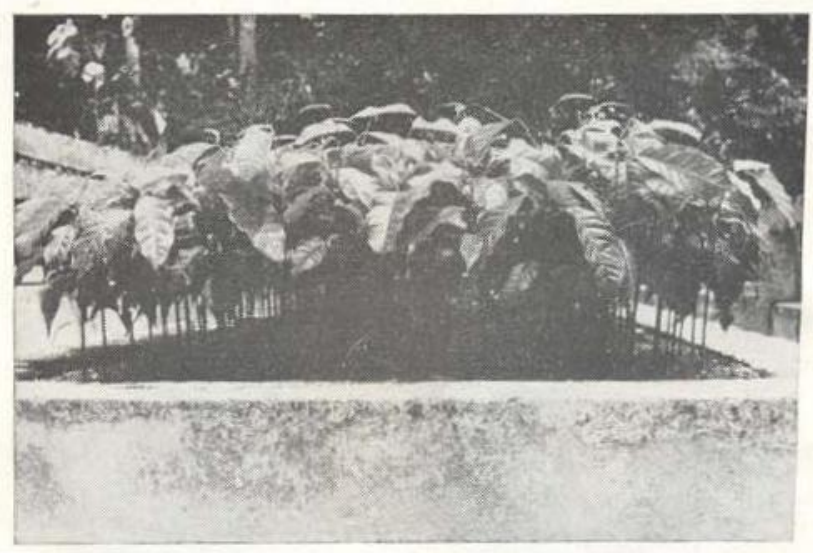

Fig. 9 - Vista do perfil do canteiro de Swietenia macrophylla King, aos 3 meses de idade Foto de Eduardo - INPA 
As sementes, pela rápida perda do poderr germinativo, podem ser armazenadas em condições naturais durante até 30 dias $(66 \%$ de germinaçãol. Sementes frescas germinam de 85 a $95 \%$.

A semeadura deve ser feita de $1,5-2 \mathrm{~cm}$ de profundidade. O solo deve ser bastante rico em matéria orgânica, permeável, porém mais argiloso do que silicoso.

A semeação nunca deve ser realizada em sacos plásticos, vasos ou outros recipientes, devido ao grande desenvolvimento do sistema radicular.

A germinação é bastante rápida, iniciandose 13 a 17 dias, durante cêrca de 10 dias.

Frutos maduros apanhados dão sementes percentualmente de maior poder germinativo, que sementes apanhadas no chão.
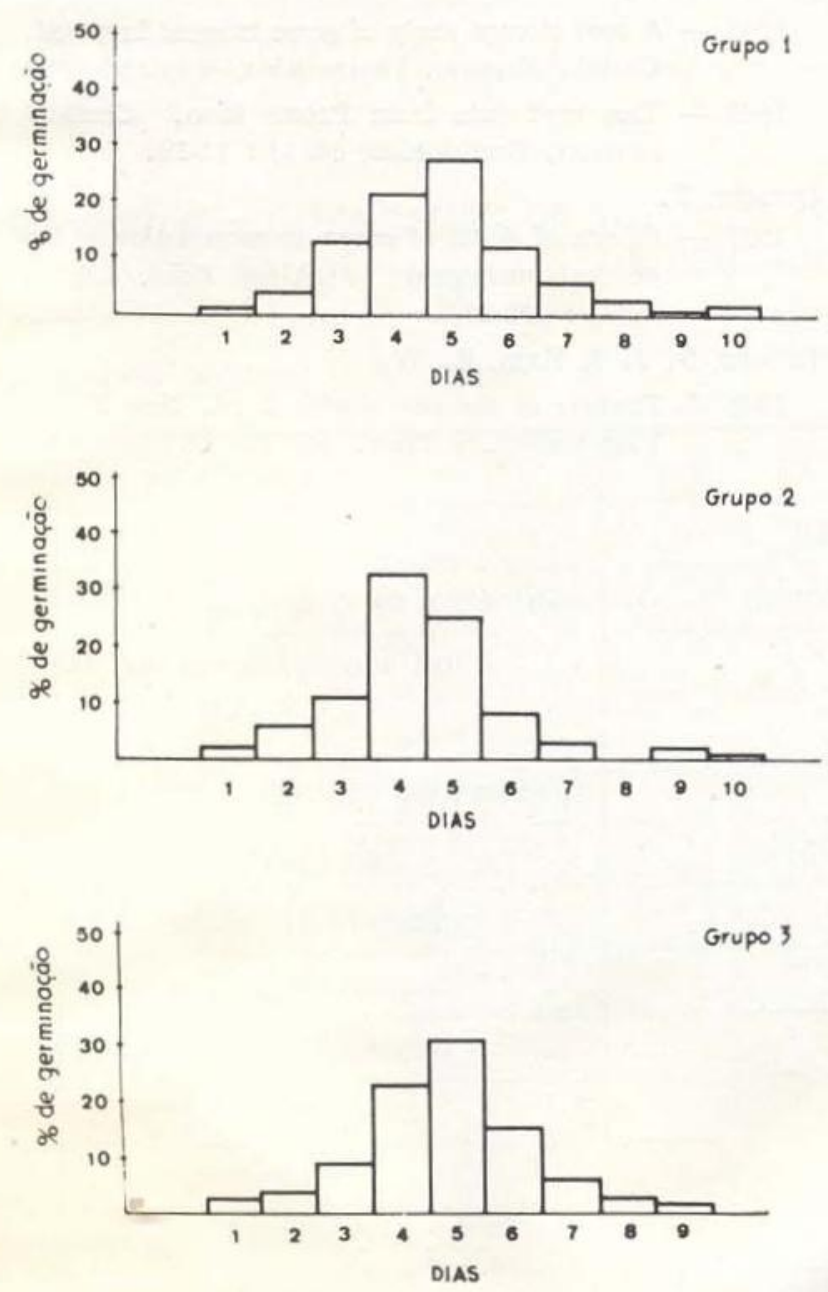

Gráfico I - Freqüência da germinação em percentagem por dias

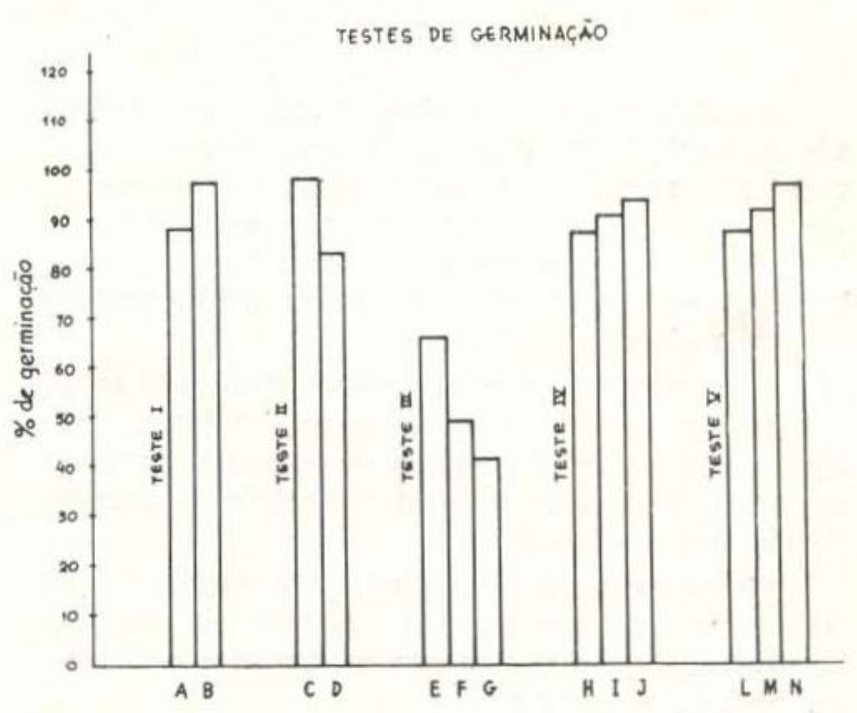
Gráfico II - Histograma comparativo do teste da

Aos 3 meses de idade, pode medir $30 \mathrm{~cm}$ de altura, aos 6 meses $60 \mathrm{~cm}$, e tamanho excelente para o plantio definitivo.

\section{COMENTÁRIOS}

Apesar da grande diferença de meio ambiente em que foram realizadas as pesquisas sôbre a germinação da Swietenia macrophylla, vamos encontrar dados que, pela pequena diferença de valores não merecem, nem podem ser tomados como êrro. Merece, no entanto, um comentário o fato dos diferentes autores aconselharem a semeadura a grande profundidade, como Quimpo (1937), de 4 a $8 \mathrm{~cm}$; Ernest Marie (1949), verticalmente a $5 \mathrm{~cm}$; Chinte (1952), em Minglanila, Cebu, de 3 a $5 \mathrm{~cm}$; em Caniaw, de 5 a $7 \mathrm{~cm}$; Bascopé (1957), de 2 a $5 \mathrm{~cm}$.

Os tratamentos usados por nós foi de $2 \mathrm{~cm}$ e $6 \mathrm{~cm}$, como extremos, tendo revelado excelente resultado a semeadura superficial $(2 \mathrm{~cm})$, enquanto a semeadura profunda $(6 \mathrm{~cm})$ foi desastrosa. Tomemos em consideração que o tipo de solo para a semeadura a $6 \mathrm{~cm}$, foi com solo permeável, leve, perfeitamente possível de boa germinação. A resistência oferecida à plântula para alcançar a superficie leva-nos a recomendar a semeadura sempre, mais superficial. 


\section{SUMMARY}

The high commercial value of mahogany, Swietenia macrophylla King, its native occurrence in Ama zonia which permits its exploitation, the absence of silvicultural research, and the different opinios of various authors are the motivations for this work. The purpose is to show its silvicultural characteristics for the region.

With botanical material (flowers, fruits and seeds) collected in Itacoatiara we were able to identify the species and perfum 5 germination tests in 13 different conditions putting to the test techniques recummended by some authors.

The following were studied: The type of seed with regard to cropping, the viability of the seed when stared, the depth of sowing, the ideal soil type, the method of sowing.

We made selection and tests of the power of germination a record of sowing, a daily count and we studied frequency and percentage of germination.

We presente figures of geographical distribution, of the botanical material, of seedlings in 4 stages of development, and plates and graphs of frequency and percentage for each of the tests.

We comment upon and present own conclusions about the germination of the species.

\section{BIBLIOGRAFIA CITADA}

BASCOPÉ, F. ET ALII

1957 - Descripciones de arboles forestables. I - Swe. tenia macrophylla King. Merida, Inst. For. Lat. Americano, 18 p.
Chinte, F. O.

1952 - Trial planting of leaf mahogany in the Phillipine Islands. Carib. Forester, Puerto Rico, 13(2): 75-84.

Garcia de Souza, F.

1967 - Mogno atrai aventureiros. Coopercutia, São Paulo, 209: 44-47.

LAMPREchet, H. \& HUecK, K.

1959 - Estudios morfológicos y ecológicos sôbre la germinacion y el desarrollo en la primera juventud de unas especies forestales en Venezuela. Merida, Inst. For. Lat. Americano. 37 p.

Marcano, A. R.

1963 - Discusión de algumas experiencias relativas a ensayos de crecimiento con la especies Cedro (Cedrela mexicana Roem) y Caoba (Swietenia macrophylla King). Bol. Inst. For. Lat. Americano, Merida, $13: 38-50$.

MARIE, E.

1949 - Notas sôbre la reforestación con Swietenia macrophylla King, en la Martinica. Carib. Forester, Puerto Rico, 10(5): 216-222.

MARRERO, J ,

1943 - A seed storage study of some tropical harwood. Caribb. Forester, Puerto Rico, 4(3) : 99-105.

1949 - Tree seed data from Puerto Rico. Caribb. Forester, Pucrto Rico, 10(1) : 11-39.

QUIMPO, T.

1937 - Effects of depth of cover on germination of large leaf mahogany. Makiling Echo, Laguna, 16(3) : 199-211.

RECORD, S. J. \& Hess, R. W.

1948 - Timbers of the ncw world. 2 ed. New Haven, Yale University Press. 640 p. 

AO TIPO DE SEMENTE - TESTE I

\begin{tabular}{|c|c|c|}
\hline DADOS OBTIDOS & A & B \\
\hline Data da colheita & $05-08-70$ & $05-08-70$ \\
\hline Procedência & Itacoatiara & Itacoatiara \\
\hline Tratamento prévio da semente & Simples escolha & Simples escolha \\
\hline Quant. de semente semeada & 329 & 300 \\
\hline $\mathrm{N} .^{\circ}$ de sementes por quilo & 1.600 & 1.500 \\
\hline Vitalidade & $92 \%$ & $100 \%$ \\
\hline Data da semeadura & $10-08-70$ & $10-08-70$ \\
\hline Início da $1 .^{\circ}$ germinação & 15 dias & 15 dias \\
\hline Duração da germinação & 10 dias & 10 dias \\
\hline Término da germinação & 25 dias & 25 dias \\
\hline Sementes germinadas & 290 & 292 \\
\hline \% da germinação & $88 \%$ & $97 \%$ \\
\hline
\end{tabular}

QUADRO ॥ - GERMINAÇÃO DE SWIETENIA MACROPHYLLA KING, QUANTO À PROFUNDIDADF DA SEMEADURA - TESTE ॥

\begin{tabular}{|c|c|c|}
\hline DADOS OBTIDOS & C & $\mathrm{D}$ \\
\hline Data da colheita & $05-08-70$ & $05-08-70$ \\
\hline Procedência & Itacoatiara & Itacoatiara \\
\hline Tratamento prévio da semente & Simples escolha & Simples escolha \\
\hline $\mathrm{N} .^{\circ}$ de sementes por quilo & 1.500 & 1.500 \\
\hline Vitalidade & $100 \%$ & $100 \%$ \\
\hline Quant. de semente semeada & 189 & 189 \\
\hline Data da semeadura & $10-08-70$ & $10-08-70$ \\
\hline Início da $1 .^{\circ}$ germinação & 15 dias & - \\
\hline Duração da germinação & 9 dias & - \\
\hline Término da germinação & 24 dias & 一 \\
\hline Sementes germinadas & 187 & 157 \\
\hline \% da germinação & $98 \%$ & $83 \%$ \\
\hline Plântulas defeituosas & $0 \%$ & $100 \%$ \\
\hline
\end{tabular}

(*) - O início, duração e término da germinação no tipo $D$, só foi observado aos 30 dias após à semeadura, quando retirada a espêssa camada de solo. 
QUADRO III - GERMINAÇÃO DE SWIETENIA MACROPHYLLA KING, QUANTO A SUA VIABILIDADE PELA ARMAZENAGEM $(30,45$ e 60 dias $)$ - TESTE III

\begin{tabular}{|c|c|c|c|}
\hline DADOS OBTIDOS & E & $\mathrm{F}$ & G \\
\hline Data da colheita & $05-08-70$ & $05-08-70$ & $05-08-70$ \\
\hline Procedência & Itacoatiara & Itacoatiara & Itacoatiara \\
\hline Tratamento prévio da semente & Simples escolha & Simples escolha & Simples escolha \\
\hline Quant. de semente semeada & 300 & 300 & 300 \\
\hline N. ${ }^{\circ}$ de sementes por quilo & 1.600 & 1.600 & 1.600 \\
\hline Vitalidade & $92 \%$ & $92 \%$ & $92 \%$ \\
\hline Data da semeadura & $04-09-70$ & $18 \cdot 09 \cdot 70$ & $05 \cdot 10 \cdot 70$ \\
\hline Início da $10^{\circ}$ germinação & 14 dias & 16 dias & 16 dias \\
\hline Duração da germinação & 12 dias & 10 dias & 14 dias \\
\hline Término da germinação & 26 dias & 26 dias & 30 dias \\
\hline Sementes germinadas & 198 & 147 & 93 \\
\hline \% da germinação & $66 \%$ & $49 \%$ & $31 \%$ \\
\hline
\end{tabular}

QUADRO IV - GERMINAÇÃO DE SWIETENIA MACROPHYLLA KING, QUANTO AO MELHOR TIPO DE SOLO — TESTE IV

\begin{tabular}{|c|c|c|c|}
\hline DADOS OBTIDOS & $\mathrm{H}$ & I & J \\
\hline Data da colheita & $05-08-70$ & $05-08-70$ & $05-08 \cdot 70$ \\
\hline Procedência & Itacoatiara & Itacoatiara & Itacoatiara \\
\hline Tratamento prévio da semente & Simples escolha & Simples escolha & Simples escolha \\
\hline Quant. de semente semeada & 200 & 200 & 200 \\
\hline $\mathrm{N} .^{\circ}$ de sementes por quilo & 1.600 & 1.600 & 1.600 \\
\hline Vitalidade & $92 \%$ & $92 \%$ & $92 \%$ \\
\hline Data da semeadura & $12-08-70$ & $12-08-70$ & $12 \cdot 08-70$ \\
\hline Início da $10^{\circ}$ germinação & 14 dias & 13 dias & 14 dias \\
\hline Duração da germinação & 9 dias & 10 dias & 10 dias \\
\hline Término da germinação & 23 dias & 23 dias & 24 dias \\
\hline Sementes germinadas & 173 & 180 & 186 \\
\hline \% da germinação & $86,5 \%$ & $90 \%$ & $93 \%$ \\
\hline$\%$ de mortalidade & - & $30 \%$ & - \\
\hline
\end{tabular}


QUADRO V - GERMINAÇÃO DE SWIETENIA MACROPHYLLA KING, EM SACO PLÁSTICO TESTE V

\begin{tabular}{|c|c|c|c|}
\hline DADOS OBTIDOS & L & M. & $\mathrm{N}$ \\
\hline Data da colheita & $05 \cdot 08 \cdot 70$ & $05-08-70$ & $05-08-70$ \\
\hline Procedência & Itacoatiara & Itacoatiara & Itacoatiara \\
\hline Tratamento prévio da semente & Simples escolha & Simples escolha & Simples escolha \\
\hline Quant. de semente semeada & 100 & 100 & 100 \\
\hline $\mathrm{N} .^{\circ}$ de sementes por quilo & 1.600 & 1.600 & 1.600 \\
\hline Vitalidade & $100 \%$ & $100 \%$ & $100 \%$ \\
\hline Data da semeadura & $10-08-70$ & $10 \cdot 08-70$ & $10-08-70$ \\
\hline Início da $1 .^{\circ}$ germinação & 15 dias & 14 dias & 14 dias \\
\hline Duração da germinação & 10 dias & 9 dias & 10 dias \\
\hline Término da germinação & 25 dias & 23 dias & 24 dias \\
\hline Sementes germinadas & 88 & $9^{\prime}<$ & 96 \\
\hline \% da germinação & $88 \%$ & $92 \%$ & $96 \%$ \\
\hline
\end{tabular}

